\title{
MEJORA DE LAS HABILIDADES COMUNICATIVAS DE LOS ALUMNOS UTILIZANDO LOS DEBATES COMO HERRAMIENTA METODOLÓGICA
}

Improving students’ communication skills using discussions as a methodological tool

Melhorar as habilidades de comunicação dos alunos usando os debates como uma ferramenta metodológica

Plan de Apoyo a la Innovación Docente 2016 de la Universidad de León (GID 09).

\section{Roberto Fernández Fernández}

Universidad de León, España. Teléfono: +34 987291398. Correo electrónico: rferf@unileon.es

\section{Resumen}

La experiencia pretende mejorar las habilidades comunicativas y exposiciones orales de los alumnos. Con ese objetivo, se utiliza como herramienta metodológica el debate, de manera que el alumno debe preparar un tema y exponerlo confrontando sus argumentos con otro compañero. Posteriormente, el profesor le indica cuáles son sus puntos fuertes y débiles y le aconseja sobre qué aspectos debe reforzar y cuáles corregir.

Palabras clave: Evaluación formativa; debates; habilidades comunicativas; exposición oral

\begin{abstract}
The experience is intended to improve students' communication skills and oral presentations. To this end, the debate is used as a methodological tool, so that the student must prepare a topic and expose it and confront his arguments with another colleague. Subsequently, the teacher tells them what are their strengths and weaknesses and advising the students you on which aspects they must reinforce or correct.
\end{abstract}

Keywords: Formative assessment; discussions; communication skills; oral presentation

\section{Resumo}

A experiência visa melhorar as capacidades de comunicação e apresentações orais dos alunos. Com esse objectivo, é utilizado como ferramenta metodológica o debate, de Mejora de las habilidades comunicativas de los alumnos utilizando los debates como herramienta metodológica 
maneira que o aluno deve preparar um tema, expõ-lo e despois confrontando os seus argumentos com um parceiro. Mais tarde, o professor diz-lhe os seus pontos fortes e fracos e aconselha sobre quais aspectos devem ser reforçados e corrigido.

Palavras-chave: Avaliação formativa; debates; capacidades de comunicação; exposição oral

\section{Introducción}

La experiencia presentada y puesta en marcha en el actual curso pretende introducir mecanismos de evaluación formativa en una asignatura jurídica, ámbito marcado tradicionalmente por pruebas finales asentadas sobre conocimientos generalmente teóricos que el alumno tiene que recordar y reproducir. Sin embargo, la introducción en esta rama del saber de experiencias sobre evaluación formativa resulta una práctica que va aumentando su importancia en el marco del sistema universitario español tras la implantación del Espacio Europeo de Educación Superior (Fernández-Fernández, 2015).

Se pretende con ello realizar un proceso de evaluación continuada, de manera que el proceso de enseñanza-aprendizaje sirva al alumno para adquirir las competencias y herramientas necesarias para que en el futuro pueda realizar exposiciones y defensas orales con cierta solvencia.

Para conseguir el anterior objetivo se utilizan dos estrategias: de una parte, el uso de los debates como herramienta metodológica para que los alumnos practiquen y mejoren sus habilidades comunicativas y exposiciones orales; de otra, aprovechar dicha actividad para incorporar elementos de retroalimentación, de manera que el profesor después de cada exposición señala a los alumnos (tanto los que exponen como los oyentes) cuáles son los aciertos y fallos de los ponentes, así como les indica consejos de cómo pueden mejorar en el futuro el lenguaje hablado, el lenguaje gestual, la ocupación del espacio, el lenguaje visual o el contenido de sus argumentos. En este sentido, "no sirve solamente con la post-información, sino que la pre-información es también crucial en ese proceso de aprendizaje del alumnado mediante la evaluación formativa” (Hamodi-Galán, López-Pastor \& López-Pastor, 2014).

De esta manera, la evaluación formativa permite desarrollar también las competencias, ya que la concepción del aprendizaje como algo activo, individualizado y Mejora de las habilidades comunicativas de los alumnos utilizando los debates como herramienta 
basado en el desarrollo cognitivo debe permitir al alumnado utilizar los conocimientos de manera creativa para resolver problemas reales (Pérez-Pueyo et al., 2008).

\section{Contextualización}

Con el fin de trabajar dos de las competencias transversales más relevantes para el Graduado en Relaciones Laborales y Recursos Humanos como son las habilidades comunicativas, así como la exposición en público, se ha adoptado como dinámica habitual la realización de debates entre alumnos sobre temas de actualidad relacionados con la Unión Europea. A tal fin, se ha seleccionado una asignatura de primer curso del Grado en Relaciones Laborales y Recursos Humanos, "Derecho Social Comunitario y Extranjería”, para que el alumno desde el primer contacto con la titulación se vaya familiarizando con las exposiciones orales y en público, que le serán tan necesarias a lo largo de sus estudios y en su futuro profesional si opta por la defensa de trabajadores y/o empresarios en juicio.

\section{Diseño y desarrollo}

A comienzo de curso, el profesor ha seleccionado una serie de asuntos que tienen que ver con temas de la máxima actualidad con la Unión Europea. El primer día de clase se les ha explicado como es la dinámica de los debates, en qué consisten, cuánto tiempo tienen que intervenir y se le han presentado los temas.

A partir de la segunda semana de clase, y una vez a la semana, cuatro alumnos (dos por tema) tendrán que preparar una de las materias propuestas por el profesor, de manera que uno tendrá que defender la postura a favor y otra la postura en contra. A tal fin, tienen una semana para buscar argumentos destinados a defender su postura, sin recibir indicaciones por parte del profesor a no ser que lo soliciten, de manera que tienen que buscar material, sobre todo a través de noticias de prensa e información en la página web de las instituciones comunitarias, para preparar su intervención oral.

Con ello, se pretende que el alumno sea el auténtico protagonista de su propio aprendizaje, pues el profesor únicamente le ha dado unas pautas generales y le presta su ayuda si la solicita. Al tiempo, se trabajan técnicas ligadas al aprendizaje significativo pues se pretende hacer ver al alumno que el contenido de la asignatura tiene aplicación práctica y que el ordenamiento comunitario no resulta un acervo lejano sino que tiene relevancia en la vida cotidiana de las personas; además, esta metodología le servirá para Mejora de las habilidades comunicativas de los alumnos utilizando los debates como herramienta 
prepararse para futuras exposiciones orales y sobre todo para presentar y defender el Trabajo Fin de Grado.

Transcurrida la semana, en la primera media hora de clase se realizan los debates, en los cuales cada uno de los alumnos tiene 5 minutos para defender su postura. Las sesiones son grabadas por los alumnos participantes en los debates con sus móviles y son facilitadas al profesor quien, además de señalar al final de cada intervención los puntos fuertes y débiles de la exposición oral, puede revisar las intervenciones con más detalle y ofrecer en tutorías posteriores el correspondiente feedback a los alumnos, visionando con ellos de nuevo la grabación con el fin de reforzar cuanto hayan hecho bien e intentar corregir los errores cometidos y todo ello con el fin último de que mejoren en el futuro sus intervenciones en público.

\section{Evaluación}

La actividad de debate es evaluable, de manera que solamente aquellos que participen en la dinámica pueden optar al 10\% de la calificación recogida en la guía docente en relación con el ítem “asistencia y participación en clase”. De igual manera, quienes decidan ser evaluados de manera continua y poder optar a presentarse a las pruebas calificables desarrolladas a lo largo del semestre deberán tomar parte en los debates, de lo contrario su calificación quedará vinculada únicamente a la realización de una prueba final.

Eso sí, como se trata de una experiencia que se está desarrollando en una asignatura impartida durante el segundo semestre todavía no se ha pasado ninguna encuesta a los alumnos a fin de comprobar su grado de satisfacción con la experiencia ni determinar si han existido progresos en la adquisición de las competencias trabajadas. Se han celebrado hasta ahora 7 debates en los cuales han participado 14 estudiantes y todos ellos han señalado la utilidad de la experiencia e indicado que les va a servir para mejorar sus exposiciones orales.

\section{Referencias}

Fernández-Fernández, R. (2015). Utilización de escala de valoración para la evaluación de las prácticas en una asignatura jurídica. En González-Fernández, N., SalcinesTalledo, I., \& García-Ruiz, E. (Coords.). Tendencias emergentes en evaluación

Mejora de las habilidades comunicativas de los alumnos utilizando los debates como herramienta metodológica 
formativa y compartida en docencia. El papel de las nuevas tecnologías (pp. 503527). Santander: Editorial de la Universidad de Cantabria.

Hamodi-Galán, C., López-Pastor, A.T., \& López-Pastor, V.M. (2014). Red de evaluación formativa y compartida en docencia universitaria: creación, consolidación y líneas de trabajo. Revista de evaluación educativa, 3(1), pp. 1-33, consultado el día 29 de marzo de 2017 en http://revalue.mx/revista/index.php/revalue/article/download/110/169

Pérez-Pueyo, A., et al. (2008). Evaluación formativa y compartida en la docencia universitaria y el espacio europeo de educación superior: cuestiones claves para su puesta en práctica. Revista de Educación, 347, 435-451. Doi: 10.4438/1988592X-0034-8082-RE

Mejora de las habilidades comunicativas de los alumnos utilizando los debates como herramienta metodológica 